\title{
The Smoking Mind: A Psycho-Cognitive Perspective *
}

\author{
by \\ Marianna Masiero $^{1,2}$, Chiara Renzi ${ }^{2}$, and Gabriella Pravettoni ${ }^{1,2}$ \\ ${ }^{1}$ Department of Oncology and Hemato-Oncology, University of Milan, Italy \\ ${ }^{2}$ Applied Research Division for Cognitive and Psychological Science, European Institute of Oncology, Milan, Italy
}

\section{SUMMARY}

Smoking behavior involves not only a biological addiction, but also psycho-cognitive components. This runs from smoking initiation, through to maintaining, attempts at quitting, and relapse. This perspective is an important element in studying and intervening in smoking behaviors. The main aim of this narrative review is to explore tobacco cigarette smoking behavior, considering the pivotal role of cognitive mechanisms embedded in decision-making and in risk judgment, with particular attention to the so-called Optimistic Bias (OB). The mechanisms through which this fallacy supports smoking initiation and continuance are explored, considering the transition from young to adult smokers and the case of light and intermittent smokers. Furthermore, additional cognitive mechanisms associated with the $\mathrm{OB}$, which sustain smoking behavior and prevent the efficacy of smoking cessation, are described. Finally, a stimulus for reflection and for discussion about how the impact of the cognitive bias perspective in tobacco cigarette smoking is provided, focusing on how it could support tailored interventions, both in smoking initiation prevention in adolescents and young adults, as well as in smoking cessation in high-risk categories. [Beitr. Tabakforsch. Int. 27 (2017) 33-41]

\section{ZUSAMMENFASSUNG}

Nicht nur die biologische Abhängigkeit, sondern auch psychisch-kognitive Komponenten spielen beim Rauchverhalten eine Rolle. Das gilt vom Rauchbeginn über das
Weiterrauchen bis zu Rauchstoppversuchen und Rückfällen. Für die Untersuchung und das mögliche Eingreifen in Rauchverhaltensmuster ist diese Perspektive ein wichtiges Element.

Das Hauptziel dieser narrativen Übersichtsarbeit besteht darin, das Rauchverhalten unter Berücksichtigung der Schlüsselrolle kognitiver Mechanismen in der Entscheidungsfindung und Risikoeinschätzung, mit besonderem Augenmerk auf dem sogenannten optimistischen Fehlschluss (Optimistic Bias), zu untersuchen. Es werden die Mechanismen, durch die dieser Trugschluss den Rauchbeginn und das Weiterrauchen fördert, dargelegt und der Übergang vom jungen zum erwachsenen Raucher sowie der Fall von leichten und gelegentlichen Rauchern betrachtet. Darüber hinaus werden weitere mit dem optimistischen Fehlschluss verbundene kognitive Mechanismen, die das Rauchverhalten aufrechterhalten und die Beibehaltung von Rauchstopps verhindern, beschrieben. Abschließend werden Anregungen zur Reflexion und Diskussion über die Auswirkungen der kognitiv verzerrten Wahrnehmung beim Rauchen von Zigaretten gegeben, in denen es darum geht, wie sie maßgeschneiderte Interventionen sowohl zur Prävention des Rauchbeginns bei Jugendlichen und jungen Erwachsenen als auch beim Rauchstopp von Menschen in Hochrisikokategorien unterstützen könnten. [Beitr. Tabakforsch. Int. 27 (2017) 33-41]

\section{RESUME}

Le comportement tabagique n'implique pas seulement une assuétude biologique mais est également guidé par des 
composantes psycho-cognitives, dès l'initiation à la cigarette, durant la consommation régulière, à chaque tentative de sevrage et à chaque rechute. Cette perspective constitue un élément important de l'étude et des interventions sur les comportements tabagiques.

Le principal objectif de la présente revue narrative est l'exploration du comportement des fumeurs de cigarettes au tabac, en considérant le rôle central des mécanismes cognitifs ancrés dans la prise de décision et l'appréciation $\mathrm{du}$ risque et en accordant une attention particulière au « parti-pris de l'optimisme ». Les mécanismes au travers desquels ce sophisme sous-tend l'initiation à la cigarette et la consommation continue sont analysés en s'attardant sur le passage des fumeurs de l'adolescence à l'âge adulte et le cas des fumeurs intermittents et légers. Par ailleurs, le texte décrit d'autres mécanismes cognitifs associés au parti-pris de l'optimisme, qui alimentent le comportement tabagique et entravent l'efficacité de la désaccoutumance au tabac. Enfin, le texte donne matière à réflexion et à discussion au sujet de l'impact du parti-pris cognitif sur le tabagisme et se concentre sur la façon dont cette perspective pourrait appuyer des interventions personnalisées tant en matière de prévention de l'initiation à la cigarette chez les adolescents et les jeunes adultes qu'en matière de sevrage tabagique pour les catégories à haut risque. [Beitr. Tabakforsch. Int. 27 (2017) 33-41]

KEY WORDS: Tobacco cigarette smoking; cognitive bias; Optimistic Bias; smoking cessation; health preventive behaviors; decision-making

\section{CONTENTS}

\section{Introduction}

2. Objectives

3. The Optimistic Bias

3.1 A general definition and brief history

3.2 The Optimistic Bias across different domains

3.3 The assessment of the Optimistic Bias: methodological considerations

4. Cognitive distortions and smoking

5. Methods

6. Smoking phases and transitions

6.1 Smoking initiation

6.2 Light and intermittent cigarette smokers

6.3 Smoking continuance

6.4 Psycho-cognitive modulators in smoking continuance, cessation, and relapse

7. General considerations for clinical interventions in tobacco use prevention

8. References

\section{INTRODUCTION}

Considering smoking merely as a nicotine addiction, which justifies the implementation of purely pharmacological interventions, fails to recognize the human dimension involved in this behavior and assigns little or no responsibility to the individual through abstinence phases. Accord- ing to this view, smokers have no explanatory power nor the possibility to implement behavioral or cognitive strategies to achieve cigarette abstinence, or to avoid the risk to relapse in abstinent smokers (1-4).

A pivotal perspective in studying and intervening on smoking behavior is related to the cognitive distortions in risk perception and false beliefs that support the smoking decision over time. In fact, smoking behavior both in the young and in the adult population is characterized by an imbalance in risk evaluation called Optimistic Bias (OB). This bias is associated with other cognitive processes that altogether favor smoking initiation, sustain its continuance $(5,6)$, and impede smoking cessation (7).

\section{OBJECTIVES}

The main aim of this paper is to explore tobacco cigarette smoking behavior both in the young and adult population from a cognitive perspective, considering the pivotal role of the cognitive bias embedded in decision-making and risk judgment, the so-called $\mathrm{OB}$, and the other cognitive mechanisms that are associated to the OB.

More specifically, this review will:

- Describe the nature of the $\mathrm{OB}$, the main cognitive process that is believed to be involved in smoking behavior. To this end, a general definition of the OB, including its application to different fields, will be provided together with methodological considerations on its use.

- Provide an overview of the cognitive and psychological factors that are involved in $\mathrm{OB}$ activation in smokers, taking into account different stages (from smoking initiation, to maintaining, quitting attempts, and relapse) and different age groups. In these sections, evidence will be reviewed showing that the $\mathrm{OB}$ is associated with the adoption of smoking behavior in adolescence. Hence, we will explore how this bias and other associated cognitive processes may sustain smoking continuance, in the attempt to overcome cognitive dissonance.

- Provide a stimulus for reflection and for discussion about how the impact of the cognitive bias approach in tobacco cigarette smoking might support tailored clinical programs, in both prevention to avoid smoking initiation or the changeover to chronic smoking in adolescents and emerging adulthood, as well as in smoking cessation interventions for high-risk categories.

\section{THE OPTIMISTIC BIAS}

\subsection{A general definition and brief history}

The OB reflects the attitude of humans to fail in risk estimation. It represents the human tendency to underrate risk and hazard when the risk concerns themselves, changing this attitude when the risk concerns other people. OB is not a personality trait, like optimism, but it is an actual imbalance in risk assessment. Such erroneous estimates, which are well below the population average, arise from the 
use of heuristics. Heuristics facilitate decision-making and problem solving (8-11), allowing decisions to be made in a fast and intuitive way (12), though they are not always immune from errors. KAHNEMAN stated that when "the heuristic mind fails, cognitive biases arise" (13). The OB may represent a serious obstacle from the viewpoint of behavioral change and preventive behaviors $(11,14)$. In fact, people who feel low levels of worry and low disease susceptibility tend to avoid preventive actions (e.g., eating healthy food, exercising regularly) (15), and are more inclined to make unhealthy decisions, such as smoking or drinking.

\subsection{The Optimistic Bias across different domains}

The OB has long been a topic of great interest in a wide range of fields, such as disease occurrence (e.g., heart diseases and skin cancer), health-related behaviors (e.g., nutrition, alcohol consumption, drinking, sexual behaviors, earthquakes, attempting suicide), crime and violence. The most extensive research is that focused on the risks related to health. For example, research conducted on diabetics has highlighted that these patients believe they are less prone to experience therapeutic complications than other diabetics (16). Also, Asians and Caucasians consider to be less exposed to the likelihood of developing skin cancer (17). The OB was found to be independent of culture, gender and age (18). GREEN and colleagues (19) reported that undergraduate students underestimated their risks of cardiovascular heart disease (CHD). Data found by GREEN stressed that only $25 \%$ judged their CHD risk as average, while $68 \%$ judged their CHD risk lower than average. GAIL and coworkers (20) performed a series of experiments on a sample of 14,000 women showing that they consistently underestimated their risk of breast cancer. Comparable results were obtained by FONTAINE and SMITH (21), who conveyed the presence of the OB for general cancer risk occurrence.

A significant analysis and discussion on the optimistic beliefs was presented by JANSEN et al. (22) that reported the attitude of overestimating the probability of therapeutic benefits in cancer patients (blood cancer, myelodysplasia, breast cancer and lung cancer) with advanced disease, who enrolled in early-phase trials. The optimistic beliefs in early-phase trials seem to be related to overestimation of drug efficacy on disease $(59.7 \%)$, health benefits $(62.5 \%)$, and avoiding side-effects of drug treatment (38.9\%).

The OB is also connected with other behaviors, such as alcohol consumption, diet, and unsafe sexual behaviors. For instance, college students believe that they themselves have a reduced probability of experiencing the proximal consequences of alcohol abuse (e.g., hangover) compared to other students under equivalent conditions (23). People believe that they follow a healthier diet than others (24) and estimate that they are less likely to contract sexuallytransmitted diseases $(18,25)$. For this reason, effective prevention campaigns are often focused on awareness (19). Regarding social problems, e.g., crime and violence, surveys such as that conducted by CHAPIN and colleagues (26) in a sample of 158 students have shown that individuals think they are less likely than their peers to become the victim of a crime.

\subsection{The assessment of the Optimistic Bias: methodological considerations}

In most recent studies, the OB has been measured in two different ways by direct and indirect methods. The direct method permits to emphasize comparative distortion in risk-perception using a single question that requires the respondents to assess their personal risk of encountering negative events or hazards compared to the average of other people. For example, "How likely do you think you are to get lung cancer compared with the average for other smokers?" or "How likely is it for you to be involved in a car accident compared to the average for other drivers?". A 7-point Likert scale is used to answer options, ranging from 1 (much below average) to 7 (much above average) $(27,28)$.

Another method to assess the OB is the indirect method. It requires that respondents provide an answer to two different questions investigating absolute and comparative risk. The first one estimates the individual likelihood to encounter some diseases or conditions (individual risk perception), using a 7-point Likert scale (ranging from 1 not at all likely to 7 extremely likely), whereas the second one requires that respondents estimate the risk that the average peer will experience concerning some diseases or conditions. If the mean difference between the second and the first item is greater than zero, an OB could be identified. Each method has its advantages and drawbacks, and may be influenced by the structure of the assessment e.g., the number of risk options presented $(28,29)$. Overall, HELWEG-LARSEN and colleagues (11) suggested that the direct method is more reliable to detect the OB compared to the indirect method. Currently, given the variety of events for which the OB can be identified, validated scales to measure the $\mathrm{OB}$ are not available (28).

\section{COGNITIVE DISTORTIONS AND SMOKING}

Past research has described smokers as individuals able to evaluate risks and benefits related to tobacco cigarette smoking (30). Smoking was thus conceived a direct consequence of a voluntary, aware and informed decision. However, SLOVIC's pioneering research on risk attitude $(31,14)$ rejected this assumption observing that smoking behavior is only "apparently rational" (32).

Since the 1980s, a growing body of literature has reported investigations into the $\mathrm{OB}$ in tobacco cigarette smokers (33-35), among which are the pioneering studies of WEINSTEIN and his research group $(25,36)$.

Smokers seem to develop optimistic beliefs about tobacco cigarette consumption and its consequences, and fail to recognize hazards related to this dependence, both in the short and in the long term (37). For instance, BORLAND and colleagues interviewed a group of smokers, asking them to assess seven possible causes of death including tobacco cigarette smoking, and six other behaviors with a lower probability rate. Only one-third of the heavy smokers chose cigarette smoking (8).

Smokers are able to find arguments and opinions to justify the underestimation of their vulnerability, overcoming the cognitive dissonance produced by risk perception and 
smoking behavior (37). Cognitive dissonance is a conflicting feeling between individual beliefs and behavior (38). According to this, people act to reduce cognitive dissonance. Smokers who are aware of hazards related to cigarettes try to overcome cognitive dissonance using rationalized explanations for their unhealthy behavior or for neglecting health information about risks (39). SIMMONS and colleagues (2004) reported that smokers may think to be unable to quit and/or they overvalue positive effects related to cigarettes (40).

Interestingly, all smokers tend to overrate their risk of developing smoking-related diseases (lung cancer, heart disease, and chronic lung pain) compared to nonsmokers, while they tend to undervalue it compared to other smokers.

Broadly speaking, smokers know the risks connected to the use of cigarettes and they are aware of possible future consequences, but they systematically neglect this information in an automatic manner when they are explicitly asked to evaluate their own risk $(5,35)$. It is important to note that people tend to maintain this positive attitude when confronted with conflicting negative information. For instance, when individuals are confronted with the frequencies of negative events in the general population, they do not update their initially optimistic estimations. On the other hand, when they receive positive information, there is a substantial update in the new estimation (41).

\section{METHODS}

Relevant literature was retrieved from searches of online bibliographic databases (PubMed, Medline, Embase, PsycINFO, and the Cochrane Library) along with authoritative texts. However, it should be noted that the present paper provides a critical perspective on the use of a cognitive approach to tobacco control and it is not intended to be a systematic review on the application of the OB across different health domains (42-44). The application of the cognitive approach to smoking is currently not very widespread in the scientific literature. For instance by using "cognitive bias" and "smoking" as starting keywords a total of 121 publications could be identified on PubMed. Considering several psycho-cognitive factors connected to the Optimistic Bias activation, we included in this review's literature interrelated concepts such as: availability heuristic, representativeness heuristic, cognitive dissonance, risk perception and decision-making processes. Sixty-three articles were selected as generally relevant to the topic. However, in view of the limited use of " $O B$ " as a keyword even in those papers which use this approach as the main topic of research, additional searches were performed through cross-referencing.

\section{SMOKING PHASES AND TRANSITIONS}

This section explores smoking behavior along a continuum. In the first sub-section, how the $\mathrm{OB}$ is associated with smoking initiation will be described, particularly focusing on adolescent smokers. The following sub-section is dedicated to the population of light and intermittent smok- ers, which is a common phenomenon in adolescents and young adults, favoring the transition to a consolidated smoking addiction. How the OB evolves in order to sustain the continuation of smoking behavior in adolescent and adult smokers will then be discussed. Finally, an overview will be given of the concurrent psychological and cognitive processes sustaining the activation of the Optimistic Bias $(16,17,23,42)$, in order to gain a better understanding of the belief system of smokers.

\subsection{Smoking initiation}

A growing body of scientific data has affirmed that more than $80 \%$ of all adult smokers begin smoking before the age of $18(45,46)$. The dual process of physiological and psychological dependence then reinforces cigarette consumption over time. Early smoking is related to higher adult smoking rates and lower probabilities of success when attempting to quit.

ARNETT and colleagues (47) conducted the first study on ageing and $\mathrm{OB}$ in adolescent and adult smokers. They observed that adolescent smokers showed higher levels of cognitive distortion in risk perception than adult smokers. In adolescents, the OB plays a strong role in the acquisition of smoking behavior. In fact, they tend to assign greater value to visceral emotions (e.g., the pleasure of smoking) (46) and to social aspects (social desirability, success, peer group influence, social identity, etc.) compared to the benefits of quitting. Concurrently, there is a systematic underestimation of the risk of becoming dependent on smoking. Indeed, $60 \%$ of adolescent smokers believe that they could smoke for a few years and then give up. Young smokers perceive themselves to be at modest risk of tobacco cigarette dependency because they believe they can quit smoking before any harm occurs $(7,14)$. As a consequence, they tend to neglect the risks of developing cancer in the next 20-30 years.

\subsection{Light and intermittent cigarette smokers}

The perceived risk of smoking is related to the number of cigarettes per day. Consistent with this, young smokers tend to consider that light cigarettes are safer than regular cigarettes, and that intermittent smoking is less harmful. Usually, intermittent and light smokers tend to underestimate the harm of cigarette consumption. They also display a tendency not to perceive themselves as "traditional" cigarette smokers, but rather as being more similar to nonsmokers $(49,50)$.

Despite these observations, intra-group differences do exist in risk perception between younger and older adolescents: older adolescents consider light smoking and intermittent cigarette smoking as more dangerous than younger adolescents (49).

\subsection{Smoking continuance}

Adolescent and adult smokers are able to identify the hazards of smoking in the long term, for instance, the risk of developing smoking-related diseases such as lung cancer and cardiovascular problems $(30,31)$. However, they seem to have a specific difficulty in attributing themselves such 
risks (51). This aspect is crucial in maintaining smoking behavior. For instance, smokers in the precontemplation stage have greater OB than those in contemplation and preparation stage (52). Consistently with this, the $\mathrm{OB}$ predicts lower cessation rates in populations affected by smoking-related diseases (53).

GERKING and colleagues (54) noted that health risk concerns are modulated by beliefs about quitting ability: those who perceive themselves as being able to quit smoking easily also tend to underestimate health risks. This trend is strong in young smokers (aged 14-20). Concomitantly, according to classic decision-making theory, individuals have difficulties in assessing the future impact and gains of the present actions in an objective manner. In other words, they prefer an immediate gain instead of a future gain, also when this is higher and more significant. This is called temporal discounting effect $(9,13)$. Thus, young smokers assign a greater value to the instantaneous effects (e.g., cognitive enhancement) and perceived advantages (as introduced in the paragraph "Smoking initiation"; e.g., achieving a social identity in peer groups, enhancing hedonistic pleasure, etc.), despite the long-term effects (e.g., respiratory and cardiovascular diseases). Recently, a longitudinal study on 228 young adolescents (mean age approximately 14 years) reported that subjects who feel invulnerable to physical harm were more likely to use cigarettes, because they overestimated the benefits related to smoking (55).

The strength of the OB in young cigarette smokers emerges in the comparison between former smokers and smokers, as revealed by a longitudinal study on 7,000 young smokers (aged between 11 and 18 years) $(45,56)$. It is interesting to note that the OB is very important in subjects who have relapsed after attempts to give up. Indeed, relapsed smokers decrease their estimated susceptibility to smoking-related diseases (14). Adult smokers affirm that they have a higher risk of developing a smoking-related disease, but at the same time, they are more optimistic about their survival threshold.

Interestingly, when older adults are exposed to undesirable information they show a reduced ability to update their beliefs as compared to younger adults (and controlling for confounding variables), while no difference is evident for desirable information (57).

\subsection{Psycho-cognitive modulators in smoking continuance, cessation, and relapse}

The chronic adoption of a hazardous behavior ("I know that cigarettes are dangerous for my health, but I cannot give up this pleasure") can dramatically decrease self-esteem ("I'm unintelligent, because I'm smoking again despite the danger to my health"). Frequently, chronic smokers feel a low self-efficacy about their capacity to quit; thus, in order to reduce anxiety regarding the health consequences they activate false beliefs as a coping strategy ("Not all cigarette smokers die from smoking"). The perceived ability to control their smoking behavior, in turn, leads smokers to the false belief that they can quit whenever they want. This effect is particularly evident in young smokers, as reported by WATERS and colleagues in a research conducted on 333 young smokers, where a higher risk perception was inversely related to the belief that nicotine addiction is remediable (58).

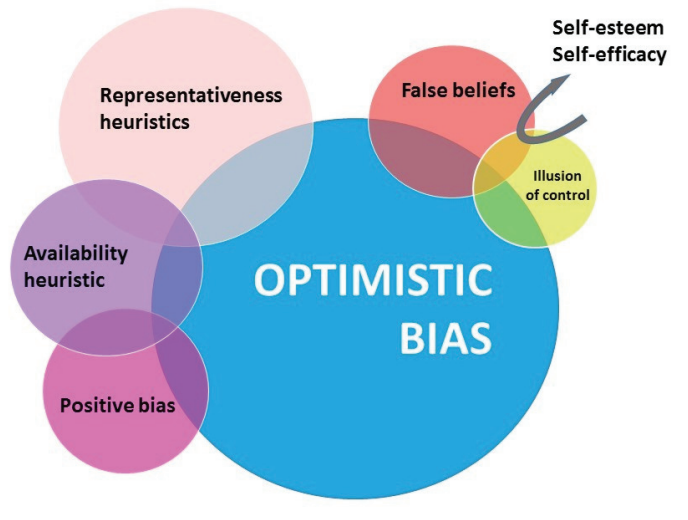

Figure 1. Optimistic Bias and related concepts. The figure represents the relations amongst the psycho-cognitive factors described in the text that are involved in the activation and in the modulation of the Optimistic Bias.

Several expressions commonly used by smokers during clinical antismoking counselling show this misconception: "I can go hours without smoking, for example, when I go to see a movie" or "If I am in an airplane for a travel it is not difficult for me not to smoke" or "I have reduced my nicotine addiction using light cigarettes." In keeping with this, studies have reported that smokers who are told that the opportunity to smoke is approaching, experience a rapid increase in craving (59-61). Conversely, if cigarettes are perceived as unavailable and the opportunity is far away, craving is decreased. As a consequence, smokers categorize smoking behavior as controllable and reversible. The more an event is considered and classified as "controllable", the greater the probability that individuals show OB (62).

Such an attitude is very common in young adult smokers and intermittent smokers, who believe they possess a high degree of control over their behavior. This aspect is of particular importance, since the capacity of nicotine in producing a physiological addiction is very fast-operating (63). Systematic underestimation of this phenomenon leads to being exposed to a high risk of becoming addicted $(32,64)$, and thus to increasing cigarette consumption over time (e.g., from 5 cigarettes per day to more than 20 cigarettes per day). Only after recurrent failed cessation attempts, cigarette smokers may come to admit that their choice is only in part voluntary or free.

Optimistic thinking is reinforced by bias associated with memory processes. Recurrent behaviors are more easily accessible, and related risks attenuated, therefore risk assessment (e.g., the likelihood of developing lung cancer) is based on specific memories rather than on objective evaluations $(36,27)$. This way, smokers activate a mnemonic mechanism analogous to the availability heuristic. It pushes individuals to draw upon the most "available" information in their memory, thus reinforcing smoking behavior (65). This process is activated by the salience of the information, indeed, salient and vivid events are recalled more easily. For example, "My grandfather smoked more than forty cigarettes per day, and he died when he was 90 years old". 
Furthermore, past experience can alter risk perception and judgment in different ways, influencing related behavior $(25,40)$. Having experienced a specific event in the past leads individuals to consider that this event will most likely be faced again in the future. For example, people who have a relative (mother, aunt, grandmother, cousin, or sister) affected by breast cancer could perceive a higher risk of this disease, and tend to regularly participate in screening programs. At the same time, the presence of a cancer case in the family could influence cigarette consumption in smokers. On the other hand, not having experienced a specific event leads individuals to believe that it will not occur soon. For example, if a smoker has never experienced cigarette-related respiratory problems, she/he may well believe that this will not happen in the near future. It is important to note that habitual smokers do not feel the side effects of smoking such as shortness of breath, coughing or mucus because they are gradually adapted to a low health condition. As a consequence, they have a real difficulty in evaluating their condition.

In keeping with these data, BETHEA and colleagues observed that smokers often had an adequate awareness about the risk of developing lung cancer from cigarette smoking, while they showed a low awareness for other smokingrelated diseases such as chronic obstructive pulmonary disease (COPD). This variability may be increased by having relatives or friends who developed the disease but never smoked (66).

Finally, two other mnemonic processes are related to the OB. The first consists of the tendency of smokers to recall positive smoking-related information more easily such as hedonistic pleasure, cognitive enhancement, and stress reduction compared to negative smoking-related information, such as coughing and disease (67). This attitude could be partially explained by another cognitive mechanism, called positive bias. This bias leads individuals to recall positive aspects instead of negative information (68). The second process is connected to the attitude of recalling the salient stereotype of a specific category of events or people, evaluating individual risk starting from the most noticeable or important features. In fact, comparative optimism is modulated by the representativeness heuristic (62). Here, individuals tend to evaluate events, objects, or people, based on the similarity they have with the stereotype of the category or class $(9,13,25)$. For numerous situations or conditions (e.g., respiratory disease, automobile accidents, suicides, alcoholism, etc.), individuals tend to create in their mind a stereotyped idea about the type of person who experiences such afflictions. When individuals do not recognize themselves according to the stereotype of the category, heuristic reasoning drives them to infer that they will never face this occurrence (65).

For instance, an adult smoker of 30 years of age, who has smoked ten cigarettes per day for ten years without developing a clear respiratory symptomatology may have a clear image of a person affected by emphysema as someone, who is older (over 60), who smokes more than 25 cigarettes per day, with serious dyspnea and mobility difficulties due to coughing and dyspnea. It follows that he will be more likely to reject the risk of this disease despite clinical evidence to the contrary, because he does not identify himself with his image of the category. Similarly, light and intermittent smokers might continue to smoke, because they do not recognize themselves in the image of a "typical" smoker (69).

\section{GENERAL CONSIDERATIONS FOR CLINICAL INTERVENTIONS IN TOBACCO USE PREVENTION}

In the previous section, it was discussed how smoking decisions may be modulated by the subjective attitude of underestimating the risks related to cigarettes. From a behavioral point of view, automatically underestimating the risk encourages adolescents to try smoking cigarettes. Later, cognitive illusions lead young adult smokers to believe that the risk of trying cigarettes is low and this attitude, in turn, favors the recurrence of cigarette use, facilitating transition from occasional smoking to chronic behavior.

According to this framework, antismoking programs should take into account the following considerations and future research should assess the efficacy of their implementation within a multidisciplinary approach.

First, interventions for adolescents should mainly be directed towards improving awareness of the risk of becoming a habitual smoker, rather than stressing the longterm consequences of cigarette smoking. In fact, this population group tends to overestimate immediate gain compared to future risks. It is therefore important to include an assessment of false beliefs, which sustain smoking initiation and trigger transition from intermittent to habitual user.

Second, promoting awareness about the benefits gained from interruption. It is important to stress the benefits related to a non-smoking lifestyle, instead of only the hazards connected to cigarette smoking. For instance, older adults are less likely than younger adults to change their beliefs when exposed to undesirable information about their future, while younger adults are more sensitive to immediate gains. Therefore, focusing intervention programs on the benefits of smoking interruption is particularly suggested for both these population groups.

Third, stressing the efficacy related to health protective behaviors. When individuals place greater trust in the efficacy of their preventive behavior (e.g., smoking cessation, healthy eating, etc.), they will be more sensitive to the benefits provided by interruption (e.g., reducing lung cancer and cardiovascular risk). As a consequence, the likelihood for success will be higher (70).

Fourth, matching the message with the individual's characteristics, beliefs and needs. For this reason, an assessment of the cognitive and psychological aspects of each person should be included in smoking cessation interventions. Fifth, modern smoking cessation intervention programs may benefit from a multidisciplinary approach which takes into account all the dimensions of smoking. Currently, investigative research as well as clinical models featuring these components are lacking and this warrants being addressed in future studies (71). A theoretical framework of smoking addiction needs to take into account biological, social, and psycho-cognitive factors, which interact reciprocally in defining a smoker's profile (4). In developing these multidisciplinary approaches, the primary aim should be for 
smokers to become aware of the processes implicated in their tobacco cigarette smoking behavior.

In line with the recent changeover to P4 (predictive, personalized, preventive, participatory) and P5 medicine, which stresses the need for a personalized approach to the patient, calling into play the psycho-cognitive dimension (72-76), we argue that an in-depth knowledge of the cognitive and emotional mechanisms involved in risk perception, decision-making, and cognitive biases is pivotal to the development of appropriate health intervention programs aimed at preventing young people from taking up cigarettes and at favoring interruption in chronic smokers. Only by recognizing the belief system of the individual and the emotional mechanisms related to risk judgment, will render it possible to develop tailored action against the epidemic phenomenon of tobacco cigarette smoking. In this vein, a knowledge of cognitive biases represents an "affordance" to communicate with the individual smoker's mind. Appropriate research should be designed and conducted in order to investigate the magnitude of possible benefits connected to the adoption of a broader perspective and of multidisciplinary approach in tobacco-related health interventions.

\section{REFERENCES}

1. Chen, D. and L.T. Wu: Smoking Cessation Interventions for Adults Aged 50 or Older: A Systematic Review and Meta-Analysis; Drug Alcohol Depend. 154 (2015) 14-24. DOI: 10.1016/j.drugalcdep.2015.06.004

2. Stanton, A. and G.M. Grimshaw: Tobacco Cessation Interventions for Young People; Cochrane Database Syst Rev., 2013.

DOI: 10.1002/14651858.CD003289.pub5

3. King, J.L., J.L. Pomeranz, and J.W. Merten: A Systematic Review and Meta-Evaluation of Adolescent Smoking Cessation Interventions that Utilized Nicotine Replacement Therapy; Addict. Behav. 52 (2016) 3945. DOI: 10.1016/j.addbeh.2015.08.007

4. Schoberberger, R., K.O. Fagerström, and M. Kunze: Psychological and Physiological Dependence in Smokers and Their Effect on Motivation for Smoking Cessation; Wien. Med. Wochenschr. 145 (1995) 70-73.

5. Masiero, M., S. Riva, C. Fioretti, and G. Pravettoni: Pediatric Blood Cancer Survivors and Tobacco Use Across Adolescence and Emerging Adulthood: A Narrative Review; Front Psychol. 7 (2016) 392.

DOI : 10.3389/fpsyg.2016.00392

6. Klein, W.M.: Optimistic Bias; National Cancer Institute, 2006. Available at: https://cancercontrol.cancer. gov/brp/research/constructs/optimistic_bias.html (accessed January 2017)

7. Song, A.V., H.E. Morrell, J.L. Cornell, M.E. Ramos, M. Biehl, R.Y. Kropp, and B.L. Halpern-Felsher: Perceptions of Smoking-Related Risks and Benefits as Predictors of Adolescent Smoking Initiation; Am J Public Health 99 (2009) 487-492. DOI: 10.2105/AJPH.2008.137679

8. Borland, R.: What do People's Estimates of Smoking Related Risk Mean?; Psychol Health 12 (1997) 513-

\section{DOI: $10.1080 / 08870449708406727$}

9. Kahneman, D. and A. Tversky: Prospect Theory: An Analysis of Decision Under Risk; Econometrica 47 (1979) 263-292. DOI: 10.2307/1914185

10. Lucchiari, C. and G. Pravettoni: Cognitive Balanced Model: A Conceptual Scheme of Diagnostic Decision Making; J Eval. Clin. Pract. 18 (2012) 82-88. DOI: 10.1111/j.1365-2753.2011.01771.x

11. Helweg-Larsen, M. and J. A. Shepperd: Do Moderators of the Optimistic Bias Affect Personal or Target Risk Estimates? A Review of the Literature; Pers. Soc. Psychol. Rev. 5 (2001) 74-95. DOI: $10.1207 / \mathrm{S} 15327957$ PSPR0501 5

12. Gigerenzer, G. and W. Gaissmaier: Heuristic Decision Making; Annu. Rev. Psychol. 62 (2011) 451-482. DOI: 10.1146/annurev-psych-120709-145346

13. Kahneman, D.: Thinking, Fast and Slow; Farrar, Straus and Giroux, New York, 2011.

14. Slovic, P., Ed.: Smoking. Risk, Perception \& Policy; Sage Publications, Thousand Oaks, CA, USA, 2001.

15. Peters, E.: The Functions of Affect in the Construction of Preferences; in: The Construction of Preference, edited by S. Lichtenstein and P. Slovic, Cambridge University Press, New York, 2006, pp. 454-463.

16. Ruthig, J.C., T.L. Haynes, R.P. Perry, and J.G. Chipperfield: Academic Optimistic Bias: Implications for College Student Performance and Well-Being; Soc. Psychol. Educ. 10 (2007) 115-137. DOI: $10.1007 / \mathrm{s} 11218-006-9002-y$

17. Luo, J. and D. Isaacowitz: How Optimists Face Skin Cancer Information: Risk Assessment, Attention, Memory and Behavior; Psychol. Health 22 (2007) 963-984. DOI: 10.1080/14768320601070951

18. Weinstein, N.D.: Unrealistic Optimism About Susceptibility to Health Problems: Conclusions From a Community-Wide Sample; J. Behav. Med. 5 (1987) 481500. DOI:10.1007/BF00846146

19. Green, J.S., M. Grant, K.L. Hill, J. Brizzolara, and B. Belmont: Heart Disease Risk Perception in College Men and Women; J. Am. Coll. Health 51 (2003) 207-211. DOI: 10.1080/07448480309596352

20. Gail, M.H., L.A. Brinton, D.P. Byar, D.K. Corle, S.B. Green, C. Schairer, and J.J. Mulvihill: Projecting Individualized Probabilities of Developing Breast Cancer for White Females Who Are Being Examined Annually; J. Natl. Cancer Inst. 81 (1989) 1879-1886. DOI: $10.1093 /$ jnci/81.24.1879

21. Fontaine, K.R. and S. Smith: Optimistic Bias in Cancer Risk Perception: A Cross-National Study; Psychol. Rep. 77 (1995) 143-146. DOI: $10.2466 /$ pr0.1995.77.1.143

22. Jansen, L.A., P.S. Appelbaum, W.M. Klein, N.D. Weinstein, W. Cook, J.S. Fogel, and D.P. Sulmasy: Unrealistic Optimism in Early-Phase Oncology Trials; IRB Ethics Hum. Res. 33 (2001) 1-8.

23. Brown, S.L. and A.M. Morley: Risk Perception, Fuzzy Representations and Comparative Optimism; Brit. J. Psychol. 98 (2007) 575-587. DOI: $10.1348 / 000712606 X 169020$

24. Miles, S. and V. Scaife: Optimistic Bias and Food; Nutr. Res. Rev. 16 (2003) 3-19. DOI: $10.1079 /$ NRR200249 
25. Weinstein, N.D.: Unrealistic Optimism About Future Life Events; J. Pers. Soc. Psychol. 39 (1980) 806-820. DOI: $10.1037 / 0022-3514.39 .5 .806$

26. Chapin, J.: Optimistic Bias Regarding Campus Violence; Curr. Res. Social Psychol. 6 (2001) 237-250.

27. Weinstein, N.D.: Why it Won't Happen to Me: Perceptions of Risk Factors and Susceptibility; Health Psychol. 3 (1984) 431-457. Available at: http://dx.doi. org/10.1037/0278-6133.3.5.431 (accessed January 2017)

28. Weinstein, N.D. and W.M. Klein: Unrealistic Optimism: Present and Future; J. Soc. Clin. Psychol. 15 (1996) 1-8. DOI: 10.1521/jscp.1996.15.1.1

29. Windschitl, P.D.: Judging the Accuracy of a Likelihood Judgment: The Case of Smoking Risk; J. Behav. Decis. Mak. 15 (2002) 19-35. DOI: 10.1002/bdm.401

30. Viscusi, W.K.: Smoking: Making the Risky Decision; Oxford University Press Inc., New York, NY, USA, 1992.

31. Slovic, P.: What Does it Mean to Know a Cumulative Risk? Adolescents' Perceptions of Short-Term and Long-Term Consequences of Smoking; J. Behav. Decis. Mak. 13 (2000) 259-266. DOI: 10.1002/(SICI)1099-0771(200004/06)13:23.3.CO;2-Y

32. Shepperd, J.A., W.M. Klein, E.A. Waters, and N.D. Weinstein: Taking Stock of Unrealistic Optimism; Perspect. Psychol. Sci. 8 (2013) 395-411.

DOI: $10.1177 / 1745691613485247$

33. Lee, C.: Perceptions of Immunity to Disease in Adult Smokers; J. Behav. Med. 12 (1989) 267-277. DOI:10.1007/BF00844871

34. Segerstrom, S.C., W.J. Mcarthy, N.H. Caskey, T.M. Gross, and M.E. Jarvik: Optimistic Bias Among Cigarette Smokers; J. Applied Soc. Psychol. 23 (1993) 1606-1618. DOI: 10.1111/j.1559-1816.1993.tb01051.x

35. Williams, T. and V.A. Clarke: Optimistic Bias in Beliefs About Smoking; Aust. J. Psychol. 49 (1997) 106-112. DOI: 10.1080/00049539708259861

36. Weinstein, N.D.: Unrealistic Optimism About Susceptibility to Health Problems; J. Behav. Med. 5 (1982) 441-460. DOI:10.1007/BF00845372

37. Weinstein, N.D., S.E. Marcus, and R.P. Moser: Smokers' Unrealistic Optimism About Their Risk; Tob. Control 14 (2005) 55-59. DOI: $10.1136 /$ tc. 2004.008375

38. Festinger, L.: A Theory of Cognitive Dissonance (Vol. 2); Stanford University Press, CA, USA, 1957.

39. Fotuhi, O., G.T. Fong, M.P. Zanna, R. Borland, H.H. Yong, and K.M. Cummings: Patterns of Cognitive Dissonance-Reducing Beliefs Among Smokers: A Longitudinal Analysis From the International Tobacco Control (ITC) Four Country Survey; Tob. Control 22 (2013) 52-58.

DOI:10.1136/tobaccocontrol-2011-050139

40. Simmons, V.N., M.S. Webb, and T.H. Brandon: College-Student Smoking: An Initial Test of an Experiential Dissonance-Enhancing Intervention; Addict. Behav. 29 (2004) 1129-1136. DOI:10.1016/j.addbeh.2004.03.005

41. Sharot, T., C.W. Korn, and R.J. Dolan: How Unrealistic Optimism is Maintained in the Face of Reality; Nat. Neurosci. 14 (2011) 1475-1479.
DOI:10.1038/nn.2949

42. Klein, C.T. and M. Helweg-Larsen: Perceived Control and the Optimistic Bias: A Meta-Analytic Review; Psychol. Health 17 (2002) 437-446.

DOI: $10.1080 / 0887044022000004920$

43. Schwarzer, R.: Optimism, Vulnerability, and SelfBeliefs as Health-Related Cognitions: A Systematic Overview; Psychol. Health 3 (1994) 161-180. DOI: $10.1080 / 08870449408407475$

44. Shepperd, J.A., G. Pogge, and J.L. Howell: Assessing the Consequences of Unrealistic Optimism: Challenges and Recommendations; Conscious Cogn. (2016) Epub ahead of print. DOI: 10.1016/j.concog.2016.07.004

45. Park, E.R., J.M. Streck, I.F. Gareen, J.S. Ostroff, K.A. Hyland, N.A. Rigotti, H. Pajolek, and M. Nichter: A Qualitative Study of Lung Cancer Risk Perceptions and Smoking Beliefs Among National Lung Screening Trial Participants; Nicotine Tob. Res. 16 (2014) 166-173. DOI: $10.1093 / \mathrm{ntr} / \mathrm{ntt} 133$

46. Bailey, S.R., S.A. Hagen, C.J. Jeffery, C.T. Harrison, S. Ammerman, S.W. Bryson, D.T. Killen, T.N. Robinson, and J.D. Killen: Randomized Clinical Trial of the Efficacy of Extended Smoking Cessation Treatment for Adolescent Smokers; Nicotine Tob. Res. 15 (2013) 1655-1662. DOI: 10.1093/ntr/ntt017

47. Arnett, J.J.: Optimistic Bias in Adolescent and Adult Smokers and Nonsmokers; Addict. Behav. 25 (2000) 625-632. DOI: 10.1016/S0306-4603(99)00072-6

48 . Loewenstein, G.F., E. Weber, C.K. Hsee, and N. Welch: Risk as Feelings; Psychol. Bull. 127 (2001) 267-268. DOI: 10.1037/0033-2909.127.2.267

49. Amrock, S.M. and M. Weitzman: Adolescents' Perceptions of Light and Intermittent Smoking in the United States; Pediatrics 135 (2015) 246-254.

DOI: $10.1542 /$ peds.2014-2502

50. Tindle, H.A. and S. Shiffman: Smoking Cessation Behavior Among Intermittent Smokers Versus Daily Smokers; Am. J. Public Health 101 (2011) e1-3. DOI: 10.2105/AJPH.2011.300186

51. Leventhal, H., K. Glynn, and R. Fleming: Is the Smoking Decision an 'Informed Choice'? Effect of Smoking Risk Factors on Smoking Beliefs; JAMA 257 (1987) 3373-3376. DOI:10.1001/jama.1987.03390240079027

52. DiClemente, C.C., J.O. Prochaska, S.K. Fairhurst, W.F. Velicer, M.M. Velasquez, and J.S. Rossi: The Process of Smoking Cessation: An Analysis of Precontemplation, Contemplation, and Preparation Stages of Change; J. Consult. Clin. Psychol. 59 (1991) 295-304.

DOI: 10.1037/0022-006X.59.2.295

53. Borrelli, B., R.B. Hayes, S. Dunsiger, and J.L. Fava: Risk Perception and Smoking Behavior in Medically Ill Smokers: A Prospective Study; Addiction 105 (2010) 1100-1108. DOI: 10.1111/j.1360-0443.2010.02900.x

54. Gerking, S. and R. Khaddaria: Perceptions of Health Risk and Smoking Decisions of Young People; Health Econ. 21 (2012) 865-877. DOI: 10.1002/hec.1760

55. Morrell, H.E., D.K. Lapsley, and B.L. Halpern-Felsher: Subjective Invulnerability and Perceptions of TobaccoRelated Benefits Predict Adolescent Smoking Behavior; J. Early Adolescence 36 (2016) 679-703. DOI: $10.1177 / 0272431615578274$ 
56. Chassin, L., C.C. Presson, J.S. Rose, and S.J. Sherman: From Adolescence to Adulthood: Age-Related Changes in Beliefs About Cigarette Smoking in a Midwestern Community Sample; Health Psychol. 20 (2001) 377-386. DOI: 10.1037/0278-6133.20.5.377

57. Chowdhury, R., T. Sharot, T. Wolfe, E. Düzel, and R.J. Dolan: Optimistic Update Bias Increases in Older Age; Psychol. Med. 44 (2014) 2003-2012. DOI: $10.1017 / \mathrm{S} 0033291713002602$

58. Waters, E.A., E. Janssen, A.R. Kaufman, L.M. Peterson, N.L. Muscanell, R.E. Guadagno, and M.L. Stock: The Relationship Between Young Adult Smokers' Beliefs About Nicotine Addiction and SmokingRelated Affect and Cognitions; J. Cancer Educ. 31 (2016) 338-347. DOI: 10.1007/s13187-015-0819-y

59. Carter, B.L. and S.T. Tiffany: The Cue-Availability Paradigm: The Effects of Cigarette Availability on Cue Reactivity in Smokers; Exp. Clin. Psychopharmacol. 9 (2001) 183-190. DOI: 10.1037/1064-1297.9.2.183

60. Dols, M., M. van den Hout, M. Kindt, and B. Willems: The Urge to Smoke Depends on the Expectation of Smoking; Addiction 97 (2002) 87-93. DOI: 10.1046/j.1360-0443.2002.00010.x

61. Thewissen, R., M. van den Hout, R.C. Havermans, and A. Jansen: Context-Dependency of Cue-Elicited Urge to Smoke; Addiction 100 (2005) 387-396. DOI: $10.1111 /$ j.1360-0443.2005.00996.x

62. Shepperd, J.A., E.A. Waters, N.D. Weinstein, and W.M. Klein: A Primer on Unrealistic Optimism; Curr Dir. Psychol. Sci. 24 (2015) 232-237. DOI: $10.1177 / 0963721414568341$

63. Benowitz, N.L.: Nicotine Addiction; Prim. Care Clin. Off. Pract. 26 (1999) 611-631. DOI: 10-1016/S0095-4543(05)70120-2

64. Otten, W. and J. Van Der Pligt: Context Effects in the Measurement of Comparative Optimism in Probability Judgments; J. Soc. Clin. Psychol. 15 (1996) 80-101.

65. Tversky, A. and D. Kahneman: Judgment Under Uncertainty: Heuristics and Biases; Science 185 (1974) 1124-1131.

66. Bethea, J., B. Murtagh, and S.E. Wallace: "I don't mind damaging my own body" A Qualitative Study of the Factors that Motivate Smokers to Quit; BMC Pub Health 15 (2015) 1-9. DOI: 10.1186/1471-2458-15-4

67. McCusker, C.G.: Cognitive Biases and Addiction: An Evolution in Theory and Method; Addiction 96 (2001) 47-56. DOI: 10.1046/j.1360-0443.2001.961474.x

68. Matlin, M.W: "Polyanna Principle"; in: Cognitive Illusions: A Handbook on Fallacies and Biases in Thinking, edited by R.F. Pohl, Taylor \& Francis, (New York, NY, USA) 2004, pp. 260.

69. Levinson, A.H., S. Campo, J. Gascoigne, O. Jolly, A. Zakharyan, and Z.V. Tran: Smoking, but not Smokers: Identity Among College Students Who Smoke Cigarettes; Nicotine Tob. Res. 9 (2007) 845-852. DOI: $10.1080 / 14622200701484987$
70. Toll, B.A., S. Martino, A. Latimer, P. Salovey, S. O'Malley, S. Carlin-Menter, J. Hopkins, R. Wu, P. Celestino, and K.M. Cummings: Randomized Trial: Quitline Specialist Training in Gain-Framed vs Standard-Care Messages for Smoking Cessation; J. Natl. Cancer Inst. 102 (2010) 96-106.

DOI: $10.1093 /$ jnci/djp468

71. Lucchiari, C., M. Masiero, A. Botturi, and G. Pravettoni: Helping Patients to Reduce Tobacco Consumption in Oncology: A Narrative Review; SpringerPlus 5 (2016) 1136.

DOI: $10.1186 / \mathrm{s} 40064-016-2798-9$

72. Gorini, A. and G. Pravettoni: P5 Medicine: A Plus for a Personalized Approach to Oncology; Nat. Rev. Clin. Oncol. 8 (2011) 444.

DOI: $10.1038 /$ nrclinonc. 2010.227-c1

73. Allenby, C.E., K.A. Boylan, C. Lerman, and M. Falcone: Precision Medicine for Tobacco Dependence: Development and Validation of the Nicotine Metabolite Ratio; J. Neuroimmune Pharmacol. 11 (2016) 1-13. DOI: 10.1007/s11481-016-9656-y

74. Chen, L.S., A. Horton, and L. Bierut: Pathways to Precision Medicine in Smoking Cessation Treatments; Neurosci. Lett. (2016) Epub ahead of print. DOI: 10.1016/j.neulet.2016.05.033

75. Prochaska, J.J. and N. L. Benowitz: The Past, Present, and Future of Nicotine Addiction Therapy; Annu. Rev. Med. 67 (2016) 467-486.

DOI: 10.1146/annurev-med-111314-033712

76. Renzi, C., S. Riva, M. Masiero, and G. Pravettoni: The Choice Dilemma in Chronic Hematological Conditions: Why Choosing is not Only a Medical Issue? A Psycho-Cognitive Perspective; Crit. Rev. Oncol. Hematol. 99 (2016) 134-140.

DOI: $10.1016 /$ j.critrevonc.2015.12.010

Corresponding author:

Marianna Masiero, Ph.D.

Department of Oncology and Hemato-Oncology

University of Milan

Via Festa del Perdono, 7

20122 Milan, Italy

E-mail: marianna.masiero@unimi.it 